\title{
School-Based Screening: A Population-Based Approach to Inform and Monitor Children's Mental Health Needs
}

\author{
Erin Dowdy $\cdot$ Kristin Ritchey $\cdot$ R. W. Kamphaus
}

Published online: 27 April 2010

(c) The Author(s) 2010. This article is published with open access at Springerlink.com

\begin{abstract}
School-based mental health professionals often conduct assessments and provide interventions on an individual basis to students with significant needs. However, due to increasingly limited resources and continuing high levels of need, a shift in service delivery is warranted. Efforts to move school psychological services from reactive and individual, to preventive and universal are ongoing. To further service delivery change, school-based mental health professionals can engage in systematic periodic mental health screening of all children. This article will (a) discuss screening for risk of emotional and behavior problems from a population-based approach, (b) describe how screening data can identify and monitor the needs of students, schools, and communities, and (c) provide future directions for screening practices. As continued changes to service delivery are imminent, information on how to utilize school-based screening data will be particularly valuable to mental health professionals working with or within schools.
\end{abstract}

Keywords Screening - Assessment - Service delivery models $\cdot$ Response to intervention $\cdot$ Mental health

\footnotetext{
E. Dowdy $(\bowtie) \cdot$ K. Ritchey

Gevirtz Graduate School of Education, Department of Counseling, Clinical, and School Psychology, University of California Santa Barbara, Santa Barbara, CA 93106, USA e-mail: edowdy@education.ucsb.edu

R. W. Kamphaus

College of Education, Georgia State University,

Atlanta, GA, USA

e-mail: edurwk@langate.gsu.edu
}

School psychology is largely operating under a Refer-TestPlace model of service delivery, in which the students are referred to a school psychologist who assesses their need for special education or related services (Cash and Nealis 2004). Service delivery is typically individually focused in case conceptualization as well as intervention, and relies on providing direct services for students at the highest level of risk. In particular, assessment has occurred on a studentby-student basis whereby each student is evaluated separately for potential risks and resources and to determine eligibility for services. In this model, school psychologists' are inefficiently being utilized to provide services primarily to a small group of students, those at the highest level of risk, and to serve as gatekeepers to special education (Kleiver and Cash 2005).

Although this service delivery approach is well-intentioned, it is unlikely that focusing on assessment and symptom reduction on an individual basis will yield meaningful improvement within a population. Not surprisingly, this individual-focused approach has thus far failed to significantly decrease rates of mental illness, with estimates suggesting that approximately $20 \%$ of children in the United States are experiencing mental, emotional, or behavioral symptoms that would qualify them for a psychiatric diagnosis in any given year (Costello et al. 2003). Furthermore, current estimates suggest that a majority of these children and adolescents at risk for emotional and behavioral problems are both unidentified and untreated (Kataoka et al. 2002; Mills et al. 2006). The high rates of children with unmet mental health needs, coupled with the limited resources that are available (Nastasi 2004), necessitate a change in the way services are provided.

For quite some time, an alternative service delivery approach, based on a public health model of service delivery, has been recommended for the treatment of 
emotional and behavioral disorders within schools (Kleiver and Cash 2005; Short 2003). In short, a public health framework differs from traditional service delivery models primarily in the explicit focus on society, as opposed to any one individual, as the population of interest and its focus on prevention, as opposed to intervention. This approach requires that individuals other than those solely at the highest level of risk receive attention (Doll and Cummings 2008b). The historical justification and implicit assumption of the public health model is that illness in one person may threaten the health of others. Theoretically, this perspective is well aligned with ecological systems perspectives, as proposed by Bronfenbrenner (1979), in which individuals and systems are mutually influential. Within an ecological framework, each student is conceptually at the center of a series of concentric circles, which represent increasingly expanding, mutually influential systems; all of these overlapping systems ultimately affect the student's well-being, and vice versa. Illness in any one person may impact another, but also the broader systems, as well. For lasting impact, change must occur at a level broader than just within an individual. To provide further guidance on how to make broad-based changes to school-based service delivery, the principals of public health can be likened to the ecological perspective already adopted by many school-based practitioners.

\section{Transforming Service Delivery within Schools}

Considering the substantial research base confirming that schools are often the major providers of mental health services for youth (Burns et al. 1995), schools are an ideal context for transforming mental health services based on a public health framework (Doll and Cummings 2008b). Indeed, this framework has provided "a roadmap for the design and development of population-based perspectives on school mental health" (Doll and Cummings, p. 7). As proposed by Nastasi (2004), school-based mental health practitioners have the opportunity to undertake a unique role in integrating the goals of public health into mental health service delivery. This integration requires a paradigm shift in service delivery from reactive and individual, to preventive and universal in scope. Accordingly, all individuals stand to benefit by creating the potential for improvement at the population level as well by reducing the epidemiology of mental health problems and the functional impairment associated with them.

Discussions in favor of a transformation toward a population-based approach within schools have been ongoing for at least the past decade with strong endorsements emanating from the 2002 Multisite Conference on the Future of School Psychology (Harrison et al. 2004). Practical recommendations for a population-based service delivery model have taken the form of a three-tiered approach. Similar to the response to intervention (RtI) movement of identifying and assisting children with academic needs, a three-tiered approach has been recommended to meet children's emotional and behavioral needs, as well (Osher et al. 2004). In this approach, universal services are provided to all youth through a school or district-wide implementation; selected or targeted services are provided to youth who are deemed at-risk; and indicated or intensive interventions are targeted for youth demonstrating the greatest level of need or impairment (Durlak 1997). Although population-based approaches are sometimes inaccurately viewed as solely providing universal, or tier one, strategies, the goals of population-based services clearly encompass universal, selected, and indicated services to promote the psychological well-being and health of all students (Doll and Cummings 2008b).

The specific work of applying public health principals to school-based service delivery within a three-tiered approach has also begun. Doll and Cummings (2008a) applied ten essential public health services, as delineated by the Institute of Medicine, to school mental health services. One of these essential services is to monitor the health status of a population to identify what health problems that community faces (Institute of Medicine 1988). A critical first step is to identify the characteristics of the problem and determine the mental health status of the population. Within schools, this typically takes the form of monitoring students' social-emotional, relational, and academic competence (Doll and Cummings 2008b).

\section{Current Approaches to Mental Health Monitoring}

Physical health indicators, such as vision and hearing, are often assessed and monitored on an individual basis through the use of a school nurse within schools. Similarly, mental health indicators have been individually assessed by a qualified mental health professional and then progress has been monitored through the use of treatment goals as outlined in a student's individualized education plan (IEP). This current practice of problem identification and monitoring at the individual level is decidedly limited in its utility and scope.

Individual-based assessment is insufficient for identifying and monitoring the mental health status of a population of students for several reasons. First, conducting mental health assessments on an individual by individual is costprohibitive, both in terms of time and personnel resources. The limited resources available make it difficult to assess all individuals within a population to garner population-based information. Additionally, the information gathered from individual-based assessment is inadequate for treatment planning. While the interventions for vision or hearing 
problems are most effective on an individual-basis (i.e. providing a student with glasses or a hearing aid), a wide body of research speaks to the value of providing schoolwide positive behavior supports (PBS) to support student's social/emotional development (e.g. Hunter 2003; Horner et al. 2002). In order for school-wide efforts to be appropriately tailored to the needs of the school, comprehensive data on the functioning of an entire body of students, rather than just a few individuals, is needed.

Unfortunately, schools have few resources to obtain systematic and evidence-based data to identify and monitor the mental health needs of a population of students (Short and Strein 2008). Recognizing this dearth of information available and the lack of empirical evidence on effective ways to monitor the mental health functioning of a population, it is logical and imperative that schools work with existing resources. One resource that is available to many schools is The Center for Disease Control's Youth Risk Behavior Surveillance System (YRBSS), an example of a population-based problem identification instrument. This survey of secondary students provides information about behaviors that pose a health risk to students, such as substance use, sexual activity, violence-related behaviors (e.g. bullying, physical abuse, use of weapons), and body weight (e.g. obesity, dieting, eating disorders). The survey also asks direct questions pertaining to sadness, hopelessness, suicidal ideation, and suicidal intent, providing insight into the mental health functioning of students. For example, students are asked, "During the past 12 months, did you ever feel so sad or hopeless almost every day for 2 weeks or more in a row that you stopped doing some usual activities?" School-based mental health professionals could utilize this information that is available to them to begin to monitor the mental health needs of students (Dowdy et al. 2010). For example, data from the YRBSS or similar surveys (such as the California Healthy Kids Survey, see www.wested.org/hks) can be used to identify the prevalence of certain mental health indicators, such as depression or behavioral problems, across primary and secondary students. This information can be compared across local, state, and national levels to begin to assist with problem identification.

Data from the YRBSS can also be analyzed across time points to provide some indication of overall and withincohort trends. Since the YRBSS is given biannually, students that are initially surveyed in the 9th grade will be re-assessed in the 11th grade, and those assessed in 10th grade will be surveyed again during 12th grade (See Fig. 1). For example, from 2003 to 2005, the students who reported seriously considering suicide decreased among both cohorts sampled; students that advanced from 9th to 11th grade decreased from 20.8 to $16.8 \%$ and students that advanced from 10th to 12th decreased from 19.0.9 to

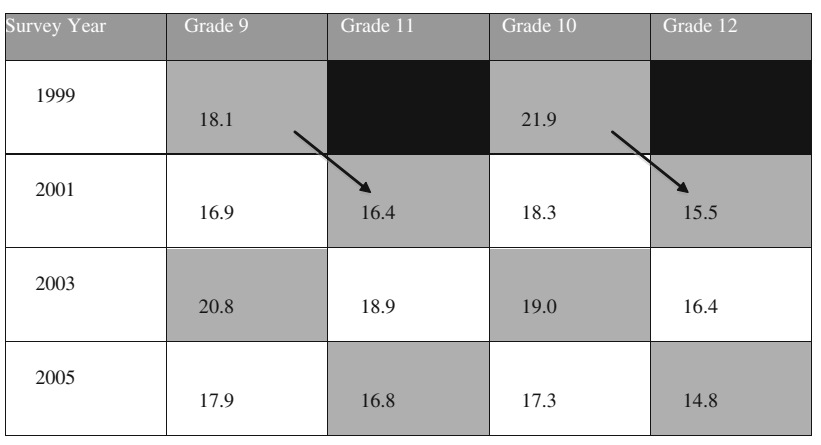

Fig. 1 Example of longitudinal population-based monitoring. Percentage of students by grade level and survey cohort year who seriously considered suicide during the 12 months before the survey from Youth Risk Behavior Surveillance Survey 1999-2005. Survey results from 1999 (Kann 2001), 2001 (Gruenbaum et al. 2002), 2003 (Gruenbaum et al. 2004), and 2005 (Eaton et al. 2006) Youth Risk Behavior Surveillance Summaries

$14.8 \%$. This continuity of respondents can provide information regarding changes among cohorts across time, which may serve as an indicator of whether the populationbased services being employed are effective.

In addition to grade level reports, data from the YRBSS and other similar surveys can also be aggregated by gender, ethnicity, and school. Although the identity of specific students is not accessible, this information still provides a method for problem identification and monitoring at the school, district, and community levels. Information obtained from the YRBSS can be useful to monitor the prevalence of certain problems, measure progress toward achieving health objectives, assess trends in health-risk behaviors, and evaluate the impact of interventions at the national, state, and local level (Kann 2001).

However, the extensive limitations of the YRBSS, one of the few sources of population-based data, further highlight the need for additional sources of information on the mental health functioning of students. In particular, the anonymous nature of these surveys, biannual administration schedule, limitations in psychometric properties, and the lack of flexibility in content limit their scope in applicability for individuals and schools. Additionally, according to the most recent publicly posted (2007) data, only 22 sites, all of which were large, mostly urban counties or cities, had a $60 \%$ or greater response rate to the YRBSS, thus yielding useable data (see www.cdc.gov/ HealthyYouth/yrbs.brief.htm). Overall, the YRBSS collects a trivial amount of information which can provide insight into the mental health functioning of students. Information on the number of students experiencing significant feelings of sadness or thoughts of suicide can be easily obtained; however, it is impossible to discern information regarding a host of other important emotional and behavioral concerns, such as inattention, hyperactivity, or anxiety. While data from the YRBSS can provide some 
minimal data that can be useful in the absence of other data, additional sources of information are needed to provide a more comprehensive picture of the mental health functioning of students.

Since data that specifically identify and monitor the mental health status of a population are limited, population-based mental health information is often collected through analysis of proxy variables. For example, examining rates of office discipline referrals or juvenile justice involvement provides an indirect link, as a higher incidence of mental health problems has been observed among those involved in the juvenile justice systems (Drerup et al. 2008). Similarly, an examination of census statistics for crime or substance abuse provides an indicator of environmental risk but little specific information on mental health rates of students. The limited data available, and little guidance on how to collect population-based information, can lead to stagnation and a continued reliance on individually based problem identification and monitoring.

\section{Population-Based Assessment}

A practical approach to population-based problem identification and monitoring has been proposed by Short and Strein (2008) in which behavioral and social epidemiological techniques are utilized. In this approach, objective information about a condition is collected (descriptive epidemiology) and built upon to examine the possible causes and influences on the condition in a population (analytic epidemiology). For example, information about the number and characteristics (age, school, gender, SES) of students with mental health concerns would be collected to calculate the incidence and prevalence rate of the problem. Then, hypotheses would be generated and tested to explain what might be causing or exacerbating the mental health problem (Short and Strein 2008).

A comprehensive service delivery system depending on regular data collection through universal screening could provide direct information allowing for both problem identification and monitoring. School-based screening has been proposed as one method for early identification of both academic (VanDerHeyden et al. 2007) and mental health (Levitt et al. 2007) problems, and the process of universally screening within a school as a part of a RtI program to determine risk status and early intervention needs is gaining momentum. By systematically engaging in periodic mental health screening of all children in schools (Hill et al. 2004), school-based mental health professionals can shift their focus away from solely providing indicated services to providing more population-based, ultimately preventive, services.

A multiple gating screening system fits well within the three-tiered model or RtI program. Initially, all children within a school are screened to identify risk factors (universal) and those children who screen positively as being at risk are provided a more in-depth assessment to determine their true risk status (selected). Finally, children who are deemed to be at-risk are provided with a comprehensive, individualized assessment (indicated) to determine precisely what their needs are. Accompanying interventions can be provided at any level. For example, suppose that following a universal screening it is found that $72 \%$ of the students in a classroom had significant symptoms of anxiety. This information suggests that a universal approach toward prevention and intervention of anxiety is the most appropriate level of intervention. Alternatively, if only two children in the classroom were screened as being at the highest level of risk, indicated services should be provided to those students. A direct and efficient utilization of resources can be easily achieved through the use of screening data to inform decisions about service provision.

The process of universally screening for academic concerns, particularly within the area of reading assessment, is becoming well-recognized and increasingly utilized. For example, the Dynamic Indicators of Basic Early Literacy Skills (DIBELS; Good and Kaminski 2002) is routinely utilized to screen for early literacy problems and monitor the development of early literacy skills (Brunsman 2003). School psychologists and other educational professionals have witnessed the value of having a systematic and proactive process in place to identify and provide early interventions to students in need. However, the process of systematic screening for emotional and behavioral problems has lagged behind, with estimates suggesting that less than $2 \%$ of schools currently utilize a systematic screening process to identify risk for mental health problems (Romer and McIntosh 2005). This lack of implementation within schools has been hypothesized to be due to a variety of factors including: the lack of technically adequate and practical screening measures (DiStefano and Kamphaus 2007); high financial and personnel costs (Romer and McIntosh); unrecognized social significance and importance of the screening by the school personnel (Lane and Beebe-Frankenberger 2004); and societal stigma for screening of mental health problems and the schools role in addressing these mental health needs (Carter et al. 2004).

However, a shift in focus toward the early identification of mental health problems (Mills et al. 2006), coupled with advances in early identification made possible through recent improvements in screening technologies (Levitt et al. 2007), have the potential to be a catalyst for change in the process of screening for mental health. In fact, school personnel have begun to react favorably to the increasing focus on early identification by endorsing a variety of large scale screening approaches to screen children for mental health risk status (Glover and Albers 2007). 


\section{Universal Screening for Population-Based Problem Identification and Monitoring}

Universally screening for emotional and behavioral problems affords the unique opportunity to collect a wide array of information from an entire population, which can be used for population-based problem identification and monitoring. Districts or local communities engaging in a universal screening program can aggregate the data and make comparisons across a number of groups or systems within that larger context to determine where significant problems and strengths exist. This system of coordinated data collection and analysis would allow for multiple agencies (e.g. schools, districts, communities) to gain a "portrait of the collective mental health of all students enrolled in a school or district" (Doll and Cummings 2008a, p. 1333). The scope of the problem and objective information about the condition can be documented. By gathering descriptive epidemiological information, analytic epidemiological techniques, in which the possible causes and influences of the problem are sought and estimated, can be employed.

A comprehensive population-based approach would also allow for screening data to be used as a method to monitor a school's mental health needs and progress. Screening data collected at different time points can be analyzed for trends across time to determine the changing prevalence and incidence of mental health problems. This goal can be accomplished using the same techniques mentioned previously when discussing the YRBSS (see Fig. 1). Monitoring the prevalence and incidence of youth problem behaviors has the potential to inform the selection of optimal prevention practices (Biglan et al. 2003), and sufficient epidemiological data can allow for schools to prioritize and direct resources into the prevention or intervention efforts that are most needed. Over time, monitoring the fluctuations in problem prevalence can provide information on the effectiveness of the interventions and services implemented and guide the planning of additional services, as needed.

Currently, the utility of this population-based approach to problem identification and monitoring is being investigated in one community in California; this community consists of a consortium of four school districts. These school districts recently received a federal grant as part of the Safe Schools/Healthy Students initiative (SSHS; see www.sshs.samhsa.gov for more information), designed to fund programs for children and communities in five major domains of functioning: school safety and violence prevention; alcohol and other drug prevention; student behavioral, emotional, and social supports; mental health services; and early childhood social and emotional learning programs. In the initial problem identification stage to determine existing problems and resources, the school districts universally administered a brief, behavioral and emotional screener. Working within existing structures, the schools co-administered a screener during a federally mandated administration of the California healthy kids survey (CHKS). Through this population-based screening, these school districts will be well-positioned to identify the behavioral and emotional functioning of the students within the entire community. Schools can individually identify the certain characteristics of the students within their schools; districts can combine school data to discuss the district's functioning; and the community can gather information from the multiple, surrounding districts to get a sense of the population's mental health functioning. Additionally, when the population-based assessment, including a social-emotional screener, is re-administered the schools will be able to monitor the status of the whole population. This may prove to be an efficient way to gauge the effectiveness of the SSHS collaborative designed to improve the mental health functioning of students within an entire community.

\section{Key Considerations for School-Based Screening}

If universal screening data with similar indicators of functioning is collected by a variety of schools and districts throughout the community, leading to the creation of local norms, insight can easily be gleaned into the particular level of interventions needed. The next section outlines the importance of a collaborative, comprehensive approach to screening with a priori decisions made regarding the constructs of interest.

\section{Constructs of Interest}

First and foremost, a decision has to be made about the relevant constructs to assess. For example, it may be pertinent for a school to screen as part of the assessment of mental health disorders (as defined by the Diagnostic and Statistical Manual of Mental Disorders, Individuals with Disabilities Education Act, or another system), or screen for the risk of developing behavioral and emotional problems, or both. The former mandates the use of discrete symptom measures and the latter requires measures of behavioral and emotional adjustment in general, ranging from frank psychopathology to the presence of more problems than are typical but yet remain below a diagnostic threshold. It is possible, however, to implement a multigate screening procedure that provides both risk assessment and diagnostic assessment through the same system simultaneously. Furthermore, an essential a priori decision about whether to collect information about the 
epidemiology of mental health disorders, in addition to the assessment of behavioral and emotional risk in a population, should be made.

While it is feasible to collect information on both risk and disorders prevalent within a population, additional resources would be needed to collect both. As screening is intended to be a quick, time-efficient process it is logical to screen only for the information that is most relevant and that could lead to efficient resource allocation. The population-based model espoused in this work is consistent with screening for risk, as opposed to screening for disorders, in order to engage in tier one and tier two early intervention and secondary prevention services. Indeed, identifying and preventing problems before they have fully developed is a cost-effective and efficient method of service delivery (Levitt et al. 2007). Furthermore, screening for a variety of different problems (e.g. externalizing, internalizing, school problems) using broad measures of maladjustment will likely be more beneficial, efficient, and useful in population-based approaches when compared to screeners that focus specifically on one disorder (e.g. depression screening, conduct disorder screening, ADHD screening).

\section{Indicators of Functioning}

One of the challenges to this proposed approach to using screening data for population-based problem identification and monitoring is the lack of uniform measures or indicators of functioning collected by various organizations. Aggregating data from a variety of sources will be most beneficial if information is collected on the same indicators, as this will allow for the creation of local norms. For example, if a number of schools and communities utilize the same tool for data collection then data can be aggregated in a meaningful and systematic way. However, if each school in the district utilizes a different approach to screening, then it will be difficult to compile the data since some approaches might solely provide indicators of externalizing problems while others may highlight the strengths and assets of students.

Indicators or measures are also not abundant, as noted earlier. The small range of available measures and methodologies suggests that this field of practice is far from mature. However, there are several screening instruments commonly utilized within schools and the recent availability of brief, time-efficient screeners could allow for an entire population (school) to be efficiently and systematically screened for emotional and behavioral problems, concerns, and strengths.

Although a comprehensive review of current screening instruments is beyond the scope of this article (see Levitt et al. 2007), Glover and Albers (2007) provide a set of criteria for school-based practitioners to utilize when evaluating universal screening instruments for potential use: (1) the appropriateness for the intended use including the match between the instrument and the objectives underlying its use; (2) the technical adequacy of the instrument; and (3) the usability of the instrument including issues such as its practicality and feasibility. Considering these criteria, Dowdy et al. (2010) identified the following commonly utilized instruments as being potentially useful for universal school-based mental health screening: Strengths and Difficulties Questionnaire (SDQ; Goodman 1997); BASC-2 Behavioral and Emotional Screening System (BESS; Kamphaus and Reynolds 2007); Pediatric Symptom Checklist (PSC; Little, Murphy, Jellinek, Bishop, \& Arnett 1994), and the Systematic Screening for Behavior Disorders (SSBD; Walker and Severson 1992).

To further highlight how universal screening can accomplish the goal of problem identification and monitoring, one approach utilizing the Behavioral and Emotional Screening System (BESS; Kamphaus and Reynolds 2007) will be described in more detail. Consistent with the recommendations offered earlier, the BESS was developed under the awareness that for a screener to be truly timeefficient and effective it should assess multiple areas of problems and strengths, including internalizing problems, externalizing problems, school problems, and adaptive skills. The BESS was designed to be completed within 5 min or less per student, with no training required and can be completed by various informants (teachers, parents, students) to identify behavioral and emotional strengths and weaknesses in youth ranging from preschool through high school (Kamphaus and Reynolds).

The BESS was normed on a sample of 12,350 teacher, parent, and student forms, collected from 233 cities in 40 states. The psychometric properties of the BESS are acceptable with high test-retest reliability estimates (.80-.91) and acceptable inter-rater reliability estimates (.71-.83). Concurrent validity with other measures of behavioral rating scales is as follows: Achenbach System of Empirically Based Assessment (ASEBA, .71-.77), Conners' Rating Scales (CRS, .51-.79), Vineland Adaptive Behavior Scales composite (Vineland, .39-.66), Children's Depression Inventory (CDI, .51), and the Revised Children's Manifest Anxiety Scale (RCMAS, .55). The BESS can be hand or computer-scored and yields a report including raw scores, $T$-scores, and percentiles with high scores reflecting higher risk. Specifically, a $T$-score of 20-60 suggests a "normal" level of risk, 61-70 suggests "elevated" risk, and 71 or higher suggests an "extremely elevated" level of risk.

The BESS can be utilized as an initial step in a multiplegating procedure to provide an assessment of mental health disorders. Following the administration of the BESS, students that are identified as having "elevated or extremely elevated risk" proceed to a second gate. In this second gate, 
the Behavior Assessment System for Children-Second Edition (BASC-2; Reynolds and Kamphaus 2004) is given; the $B A S C-2$ is a comprehensive, omnibus rating scale that provides additional information regarding the specific areas which might be problematic for the positively screened. Through this second gate assessment, it might become apparent that the student is experiencing significant problems with hyperactivity as opposed to depression. A third gate assessment can be utilized to gather more comprehensive information, incorporating multiple sources of information, to aid in diagnostic and treatment planning. While multiple-gates are not needed to identify and monitor the mental health status of a population of students, this detailed follow-up could be conducted at the selected and indicated levels.

Although it is a newly developed instrument, the utility of screening for problem identification and monitoring using the BESS is promising. Current research is underway in which the BESS is being used to universally screen an entire population of students across several schools. Teachers and parents at the elementary level and students at the secondary level have been engaged in a routine, systematic screening procedure. Through the use of the screening tool and its analytic software, schools have been able to pinpoint the exact percentage of students who are at significant risk of developing an emotional or behavioral problem. Additionally, when used district-wide, districts can determine if there are significant differences across school sites, grade levels, or student characteristics (age, sex, race/ethnicity).

In this recent investigation utilizing the BESS to screen a population of students, the vast majority of students in this study (at least $80 \%$ of all samples) were found to not be at an elevated risk (Kamphaus et al. 2010). Research such as this may help to subdue the relatively prevalent fears that screening will simply identify more problems that can be tended to. Additionally, the BESS was found to be useful for identifying both externalizing and internalizing problems in students with no differences among students classified in regards to student race/ethnicity or free/reduced lunch status. While screening did categorize more boys than girls as being "at risk," the differences were fewer than differential placement rates that currently exist in special education. The data obtained from conducting a population-based assessment allowed for detailed problem identification. As future screenings are conducted, it will be possible to also monitor the mental health status of these students.

\section{Local Norms}

Creating local emotional, behavioral, and mental health norms would require a similar effort to the creation of local educational (e.g. reading, mathematics) norms that are burgeoning within response-to-intervention programs at schools (Vaughn et al. 2003). Curriculum-based measurements of oral reading fluency, for example, are used to compare the relative achievement of students within a specific classroom, grade level, school, or community. Comparisons are facilitated by utilizing the same tool across time to collect information on reading fluency. By analyzing the specific characteristics of the population across time, it could be determined that boys have higher prevalence rates of reading problems and that in particular, boys in schools with no after-school programming are at greatest risk. Similarly, such local norms would also be useful to identify the prevalence and incidence of emotional and behavioral problems (e.g. depression) across different groups.

Local, commonly referred to as subgroup, norms can be beneficial in a variety of ways. First, if local norms are created at the school level, it will be easy to ascertain if there are any particular students or classrooms that are outliers, signifying that the child may be experiencing an unusual amount of distress. Second, if the local norms are created at a district level then it will be easy to determine if there are any particular schools that are outliers. This might indicate that there are significant difficulties within one school, when compared to its neighboring schools. Hypotheses regarding the reasons that students at certain schools appear to be at higher risk of developing mental health problems than those at other schools could be generated. For example, is the afflicted school in a neighborhood with limited resources? Does the school have a dearth of preventative programming when compared to neighboring schools? Finally, local norms could be created at a community level by incorporating information from a multiple school districts in the area. By examining these data for outliers, one could determine if certain school districts are experiencing more distress, and subsequently begin the process of determining why that may be.

Local norms also have limitations, the foremost being that norms cannot provide information for diagnostic purposes. One cannot, for example, create separate diagnostic criteria for men and women for breast cancer and heart disease, or girls and boys for ADHD, depression, and conduct disorder based on information obtained by local norms. Consequently, subgroup norms are best used for intervention and prevention planning purposes.

\section{Implications for School Psychology Research and Practice}

At the school level, school-based mental health practitioners can be instrumental in advancing the practice of 
population-based screening and are ideally positioned to take a leadership role in the early identification process. Clearly, school psychologists could not be solely responsible for screening all children within a population; this can be better accomplished by having teachers, parents, or the students themselves complete brief behavioral rating scales. Then, through the use of scanning and analytic software, school psychologists could easily interpret results and disseminate findings. A variety of additional roles and functions can be performed by school-based mental health practitioners including: establishing a planning and implementation team; determining the specific rationale and goals for screening within their school; evaluating screening tools and choosing an instrument that aligns with the goals; identifying the resources that are available to provide interventions based on screening results; determining the timeline for implementation and process for collecting screening data; disseminating results; providing feedback to teachers, schools, and individual students; analyzing and summarizing data for district-level reporting; linking screening outcomes to services and interventions; and evaluating the screening process (Dowdy et al. (2010). Furthermore, school-based mental health practitioners can serve as a liaison between various mental health and educational organizations in the community and facilitate cross-collaborations among agencies.

The work of population-based mental health identification and monitoring is not limited to within schools; in fact, through effective collaboration, communities could be better positioned to inform and monitor children's mental health needs within the broader community context. Working within an ecological framework, it is apparent that problems do not solely exist within a child but are a function of interactions between the child and a multitude of environments. Therefore, it is not surprising that organizations, schools, families, and community agencies working independently to improve the lives of children often fall short of having the meaningful impact that could be possible if their efforts were collaborative and synergistic toward the same goals. Partnerships within the community would most certainly strengthen the effectiveness of this proposed population-based approach to problem identification and monitoring and the subsequently resulting interventions. For example, if schools are aware that there has been an increase in disruptive behavior problems in their neighborhood, they can partner with local family service providers and community organizations to implement appropriate evidence-based interventions. Similarly, if service providers were aware of trends, they would be able to coordinate services in a more time- and costefficient manner.

A community collaborative to inform, monitor, and treat student's mental health necessitates a significant partnership among key stakeholders. Leff et al. (2004) describe a partnership-based framework, based on the participatory action research (PAR) model also used by Nastasi et al. (2000), as an effective way to utilize data to inform and sustain intervention implementation. Working within this framework involves integrating empirically established methods with input from key community stakeholders, in essence adapting evidence-based strategies to meet the particular needs of the school and community with whom they are working. A major strength of this approach is its utility in prevention programming, in that it allows a school-based mental health researcher or practitioner to impact an entire school population. This approach progresses through several steps, the first of which is population-based assessment or problem identification. Next, the team conducts a problem analysis, wherein the research team shares their preliminary findings with their collaborators to ensure that their interpretation of the information gathered is an accurate reflection of the school partners' perspectives. Subsequently, a culturally relevant and realistic program is developed and implemented to address the areas of concern. Finally, researchers and school partners agree upon an appropriate way in which to evaluate the success of the new intervention. The active input of school partners is a requisite component of the program in which researchers, school partners, and the school population all stand to benefit. Partnerships utilizing these key components of participatory action may have more success when working together to identify and treat mental health problems within the community.

As limited research currently exists on the use of universal screening to monitor and inform children's mental health, the need for empirical evidence supporting this approach is pressing. A first step involves pilot testing universal screening tools to determine their appropriateness specifically for problem identification and mental health monitoring; the practicality and feasibility of this approach should be tested (Glover and Albers 2007). Additionally, the social significance of the screening, the social acceptability of the procedures, and the social importance of the effects produced by the screening should be considered (Lane and Beebe-Frankenberger 2004). Unfortunately, few studies of school-wide interventions have included measures of social validity and it has been posited that the absence of such information can help explain why some interventions fail (Lane and Beebe-Frankenberger).

Important questions remain about the long-term costs and benefits of screening, predictive validity of measures, the relative benefit of using various informants and multiple gates or stages, and paucity of strong outcome or criterion variables. Additionally, the accuracy of some screening procedures has been questioned, with some studies suggesting that predictive validity of screening 
methodologies is limited (Najman et al. 2007; Roberts et al. 2008). Additional research is warranted that examines the optimal role of partnerships, the feasibility and accuracy of screening, as well as the link from problem identification and monitoring to actual intervention and prevention. These knowledge gaps do not obviate the current need for screening; in fact, the implementation of screening can hasten the research enterprise as well (VanDeventer and Kamphaus in press).

\section{Limitations}

This proposed approach to problem identification and monitoring is possible and necessary; however, it is not without its own set of limitations and barriers. Schoolbased screening efforts, particularly with regard to mental health problems, have been controversial and have raised both ethical and practical concerns (Kratochwill 2007). Concerns include issues regarding passive versus active consent for screening, how to handle the potential increase in services that may be required with an increase in youth identified as being in need, the potentially time-consuming nature of any population-based data effort, and how to conduct screening in a way that is unobtrusive and not ecologically disruptive to the school. Details regarding how and when to collect the data must be tended to. Timing the administration of a survey to align with other standardized testing may be practical, but since testing often occurs late in the year there is an additional time pressure to follow-up with students who are found to be at risk. Additional concerns regarding the expense of conducting a schoolwide effort, both in terms of personnel time and monetary resources, particularly in current times of budget reductions and furloughs, have also surfaced. A re-allocation of special education resources may prove effective for funding and sustaining a screening program. Additionally, an established community collaborative, in which data and resources are shared across multiple agencies, could allow for cost-sharing, thus minimizing the financial burden on any one school, district, or community mental health agency.

It may prove feasible to provide follow-up assessment and intervention to students who screen as "at risk" solely within the school environment. This will also require a re-allocation of resources wherein school-based mental health professionals are utilized to primarily provide population-based services instead of relying solely on providing direct services. By catching students early in their mental health trajectories through systematic, universal screening and by providing resulting early interventions, it should theoretically lessen the number of students who later develop more significant problems warranting tertiary services. However, some schools may have limited resources available to them, and thus may need to coordinate with mental health agencies to make community referrals. Questions about how best to provide this coordination and seamless service provision, along with questions about whether school-based screening necessitates that schools provide interventions to all students who screen positive, are present. A thorough understanding of the limitations of this approach provides insight into why this type of population-based assessment has not been consistently implemented. Additionally, it provides direction for future research needs.

\section{Conclusions}

Each year significant federal, state, and community funds are dedicated to improve the mental health outcomes for children. However, each year this aim is not met and the current system falls short. Additional funding for mental health and related areas are always sought after, but in lieu of unlimited funding, adjustments to current practice are requisite. The key step in reform is to move school-based psychological services from the back of the service delivery system, in which only students at the highest level of risk receive services, to the front of service delivery through the use of universal, proactive screening. Additionally, public health officials may be well served to consider partnering with local schools and communities to collect this detailed level of information on the mental health status of students in an effort to better understand the shortcomings of the current mental health care system. A continued focus on early identification and early intervention is necessary.

By taking this public health approach to problem identification and monitoring, school-based mental health professionals may start to impact the larger population and truly begin to provide population-based services. Schoolbased mental health professionals possess a unique skill set with a solid understanding of statistics, measurement, consultation, and school-family community partnerships. Additionally, they needed access to school records, school officials, and community stakeholders who can help to effect change. The arguments presented earlier provide evidence and a call to action for school-based mental health professionals to expand their role to include population-based services utilizing school-based screening data to identify and monitor the mental health needs of students.

Population-based indicators of functioning are needed to not only help determine the incidence and prevalence of mental health problems but also to help determine the future course of action. The paradigm shift to one of population-based assessment and monitoring goes beyond a change in the daily practice of school mental health 
practitioners and psychologists, but also has implications for how mental health is conceptualized within society. When adopting the public health viewpoint that the health or illness of one individual affects an entire population, a coordinated effort to provide assessment and prevention for all, and intervention for those in need is certainly warranted.

Open Access This article is distributed under the terms of the Creative Commons Attribution Noncommercial License which permits any noncommercial use, distribution, and reproduction in any medium, provided the original author(s) and source are credited.

\section{References}

Biglan, A., Mrazek, P. J., Carnine, D., \& Flay, B. R. (2003). The integration of research and practice in the prevention of youth problem behaviors. The American Psychologist, 58, 433-440.

Bronfenbrenner, U. (1979). The ecology of human development: Experiments by nature and design. Cambridge, MA: Harvard University Press.

Brunsman, B. A. (2003). Review of the DIBELS: Dynamic indicators of basic early literacy skills. In B. S. Plake, J. C. Impara, \& R. A. Spies (Eds.), The fifteenth mental measurements yearbook (6th ed., pp. 307-310). Lincoln, NE: Buros Institute of Mental Measurements.

Burns, B. J., Costello, E. J., Angold, A., Tweed, D., Stangl, D., Farmer, E. M. Z., et al. (1995). Children's mental health service use across service sectors. Health Affairs, 14, 149-159.

Carter, A. S., Briggs-Gowan, M. J., \& Davis, N. O. (2004). Assessment of young children's social-emotional development and psychopathology: Recent advances and recommendations for practice. Journal of Child Psychology and Psychiatry, 45(1), 109-134.

Cash, R. E., \& Nealis, L. K. (2004). Mental health in the schools: It's a matter of public policy. Paper presented at the National Association of School Psychologists Public Policy Institute, Washington, DC.

Costello, E. J., Mustillo, S., Erkanli, A., Keeler, G., \& Angold, A. (2003). Prevalence and development of psychiatric disorders in childhood and adolescence. Archives of General Psychiatry, 60, 837-844.

DiStefano, C. A., \& Kamphaus, R. W. (2007). Development and validation of a behavioral screener for preschool-age children. Journal of Emotional and Behavioral Disorders, 15(2), 93-102.

Doll, B., \& Cummings, J. (2008a). Best practices in population-based school mental health services. In A. Thomas \& J. Grimes (Eds.), Best practices in school psychology $V$ (pp. 1333-1347). Bethesda, MD: National Association of School Psychologists.

Doll, B., \& Cummings, J. (2008b). Why population-based services are essential for school mental health, and how to make them happen in your school. In B. Doll \& J. Cummings (Eds.), Transforming school mental health services: Population-based approaches to promoting the competency and wellness of children. Thousand Oaks, CA: Corwin Press.

Dowdy, E., Furlong, M., Eklund, K., Saeki, E., \& Ritchey, K. (2010). Screening for mental health and wellness: Current school-based practices and emerging possibilities. In B. Doll, W. Pfohl, \& J. S. Yoon (Eds.), Handbook of youth prevention science. New York: Routledge.

Drerup, L. C., Croysdale, A., \& Hoffmann, N. G. (2008). Patterns of behavioral health conditions among adolescents in a juvenile justice system. Professional Psychology: Research and Practice, 39(2), 122-128.

Durlak, J. A. (1997). Successful prevention programs for children and adolescents. New York: Plenum Press.

Eaton, D. K., Kann, L., Kinchen, S. A., Ross, J. G., Hawkins, J., Harris, W. A., et al. (2006). Youth risk behavioral surveillance United States, 2005. Morbidity and Mortality Weekly Report, 55, SS-5.

Glover, T., \& Albers, C. (2007). Considerations for evaluating universal screening assessments. Journal of School Psychology, 45(2), 117-135.

Good, R. H., \& Kaminski, R. A. (Eds.). (2002). Dynamic indicators of basic early literacy skills (6th ed.). Eugene, OR: Institute for the Development of Education Achievement. Available at http://dibels.uoregon.edu.

Gruenbaum, J., Kann, L., Kincjen, S. A., Williams, B., Ross, J. G., Hawkins, J., et al. (2004). Youth risk behavior surveillance United States, 2003. Morbidity and Mortality Weekly Report, 53, SS-2.

Gruenbaum, J., Kann, L., Kincjen, S. A., Williams, B., Ross, J. G., Lowrey, R., et al. (2002). Youth risk behavioral surveillance United States, 2001. Morbidity and Mortality Weekly Report, 51, SS-4.

Harrison, P. L., Cummings, J. A., Dawson, M., Short, R. J., Gorin, S., \& Palomares, R. (2004). Responding to the needs of children, families, and schools: The 2002 multisite conference on the future of school psychology. School Psychology Review, 33, 12-33.

Hill, L. G., Lochman, J. E., Coie, J. D., Greenberg, M. T., \& The Conduct Problems Prevention Research Group. (2004). Effectiveness of early screening for externalizing problems: Issues of screening accuracy and utility. Journal of Consulting and Clinical Psychology, 72, 809-820.

Horner, R., Sugai, G., \& Gresham, F. (2002). Behaviorally effective school environments. In M. R. Shinn, H. M. Walker, \& G. Stoner (Eds.), Interventions for academic and behavior problems II (pp. 315-350). Bethesda, MD: National Association of School Psychologists.

Hunter, L. (2003). School psychology: A public health framework III. Managing disruptive behavior in schools: The value of a public health and evidence-based perspective. Journal of School Psychology, 41, 39-59.

Institute of Medicine. (1988). The future of public health. Washington, DC: National Academy Press.

Kamphaus, R. W., DiStefano, C., Dowdy, E., Eklund, K., \& Dunn, A. (2010). Determining the presence of a "problem": A comparison of teacher screener test development methodologies for detection of behavioral and emotional risk. Manuscript submitted for publication.

Kamphaus, R. W., \& Reynolds, C. R. (2007). Behavior assessment system for children-second edition (BASC-2): Behavioral and Emotional Screening System (BESS). Bloomington, MN: Pearson.

Kann, L. (2001). The youth risk behavior surveillance system: Measuring health-risk behaviors. American Journal of Health Behavior, 25(3), 272-277.

Kataoka, S. H., Zhang, L., \& Wells, K. B. (2002). Unmet need for mental health care among U.S. children: Variation by ethnicity and insurance status. American Journal of Psychiatry, 159, $1548-1555$

Kleiver, A., \& Cash, R. E. (2005). Characteristics of a public health model of a mental health service delivery. Communique, 34(3), 19.

Kratochwill, T. R. (2007). Preparing psychologists for evidence-based school practice: Lessons learned and challenges ahead. American Psychologist, 62, 829-843.

Lane, K. L., \& Beebe-Frankenberger, M. (2004). School-based interventions: The tools you need to succeed. Boston: Pearson. 
Leff, S. S., Costigan, T., \& Power, T. J. (2004). Using participatory research to develop a playground-based prevention program. Journal of School Psychology, 42, 3-21.

Levitt, J. M., Saka, N., Romanelli, L. H., \& Hoagwood, K. (2007). Early identification of mental health problems in schools: The status of instrumentation. Journal of School Psychology, 45, 163-191.

Mills, C., Stephan, S. H., Moore, E., Weist, M. D., Daly, B. P., \& Edwards, M. (2006). The President's New Freedom Commission: Capitalizing on opportunities to advance school-based mental health services. Clinical Child and Family Psychology Review, 9(3), 149-161.

Najman, J. M., Heron, M. A., Hayatbakhsh, M. R., Dingle, K., Jamrozik, K., Bor, W., et al. (2007). Screening in early childhood for risk of later mental health problems: A longitudinal study. Journal of Psychiatric Research, 42, 694-700.

Nastasi, B. (2004). Meeting the challenges of the future: Integrating publich health and public education for mental health promotion. Journal of Educational and Psychological Consultation, 15(3), 295-312.

Nastasi, B. K., Varjas, K., Schensul, S. L., Silva, K. T., Schensul, J. J., \& Ratnayake, P. (2000). The participatory intervention model: A framework for conceptualizing and promoting intervention acceptability. School Psychology Quarterly, 15, 207-232.

Osher, D., Dwyer, K., \& Jackson, S. (2004). Safe, supportive, and successful schools: Step by step. Cambridge: Blackwell.

Reynolds, C. R., \& Kamphaus, R. W. (2004). Behavior assessment system for children-second edition (BASC-2). Circle Pines, MN: AGS.

Roberts, N., Stuart, H., \& Lam, M. (2008). High school mental health survey: Assessment of a mental health screen. Canadian Journal of Psychiatry, 53, 314-322.
Romer, D., \& McIntosh, M. (2005). The roles and perspectives of school mental health professionals in promoting adolescent mental health. In D. L. Evans, E. B. Foa, R. E. Gur, H. Hendin, C. P. O'Brien, M. E. P. Seligman, \& B. T. Walsh (Eds.), Treating and preventing adolescent mental health disorders: What we know and what we don't know (pp. 598-615)). New York: Oxford University Press.

Short, R. J. (2003). Commentary: School psychology, context, and population-based practice. School Psychology Review, 32, $181-184$.

Short, R. J., \& Strein, W. (2008). Behavioral and social epidemiology: Population-based problem identification and monitoring. In B. Doll \& J. Cummings (Eds.), Transforming school mental health services: Population-based approaches to promoting the competency and wellness of children. Thousand Oaks: Corwin Press.

VanDerHeyden, A. M., Witt, J. C., \& Gilbertson, D. (2007). A multiyear evaluation of the effects of a response to intervention (RTI) model on identification of children for special education. Journal of School Psychology, 45, 225-256.

VanDeventer, M. C., \& Kamphaus, R. W. (in press). Mental health screening at school: Instrumentation, implementation, and critical issues. New York: Springer.

Vaughn, S., Linan-Thompson, S., \& Hickman, P. (2003). Response to instruction as a means of identifying students with reading/ learning disabilities. Exceptional Children, 69(4), 391-409.

Walker, H. M., \& Severson, H. H. (1992). Systematic screening for behavior disorders (2nd ed.). Longmont, CO: Sopris West. 